\title{
A VIOLA E SUAS METALINGUAGENS: NOTAÇÃO DO GESTO E APRENDIZADO NÃO FORMAL'
}

\section{THE VIOLA AND ITS METALANGUAGE: NOTATION OF GESTURE AND NON-FORMAL LEARNING}

\author{
Gisela G. P. Nogueira \\ Universidade Estadual Paulista \\ ganogueira@uol.com.br
}

\section{Resumo}

aprendizado da notação musical foi historicamente associado às camadas privilegiadas da sociedade. Assim o descrevem os textos amplamente conhecidos das áreas de História da Música e Musicologia. Temos por certo, contudo, tratarem de um excerto da produção musical, dado que a prática popular excede, em grande número, a das elites. $\bigcirc$ levantamento histórico das fontes de documentação musical de que se serviram tratou, exclusivamente, da música escrita em notação convencional e, em larga escala, de manuscritos e publicações até fins do século XIX. A partir da institucionalização do aprendizado musical com o advento dos conservatórios, surgiu a demanda por publicações de textos didáticos que uniformizassem o conhecimento musical.

De outro lado, as cordas dedilhadas e, particularmente, as guitarras ou violas, serviram à produção musical de todas as camadas da sociedade, desde suas origens árabes, até a difusão pela Europa e por suas colônias. Seu aprendizado se deu por meio não formal, seja pela tradição oral ou não letrada, seja por outras formas de letramento (possivelmente a razão de sua enorme popularidade), desconsideradas naquelas publicações didáticas, à exceção de pequenas citações ao alaúde e às vihuelas. A institucionalização mesma do ensino desses instrumentos ocorreu muito tardiamente em relação aos instrumentos de orquestra e ao piano.

\footnotetext{
I Conferencia apresentada no dia 20 de outubro de 2016, como parte da programação do VII Encontro de Musicologia de Ribeirão Preto - A viola Caipira na universidade: o regional, o local e o universal.
} 
Das representações utilizadas nas formas de letramento formal e não formal, a notação da produção instrumental das cordas dedilhadas reúne a notação do gesto, inclusa em um sistema próprio de signos conhecido como Tablaturas, cujos registros mais antigos datam do final do século XV, e Alfabetos Musicais (muito utilizados nos séculos XVII e XVIII). $\bigcirc$ letramento através dessa notação é, ainda hoje, amplamente utilizado nos meios informais de aprendizado das cordas dedilhadas. A especificidade de tal sistema promoveu a obliteração desses registros históricos dos textos didáticos e do letramento formal até recentemente. A Universidade brasileira ainda não os trouxe à luz.

\section{Abstract}

The learning of musical notation has been historically associated with the privileged strata of society, as described by the widely known texts of Music History and Musicology. We certainly address it as an excerpt from the musical production as the popular practice exceeds, in large number, the elite ones. The historical survey of musical documentation sources used in this bibliography delt exclusively with conventional musical notation and on a large scale, with manuscripts and publications up to the late nineteenth century. With the institutionalization of musical learning and the foundation of the conservatories, came the demand for textbooks that standardized musical knowledge.

On the other hand, plucked strings and especially the guitars, served the musical production from all the society strata, ever since its Arab origins, to the spread across Europe and its colonies. His learning was through non-formal ways, either by oral or nonliterate tradition, or other forms of literacy (possibly the cause of its enormous popularity) wich were disregarded on those educational publications, except for short quotations to the lute and the vihuelas. The institutionalization of these instruments occurred very late in relation to those of the orchestra and the piano. From the representations used in formal literacy and non-formal ones, the musical notation of plucked strings instruments include the notation of gestures in a system of signs known as tablature, whose earliest 
records date back to the late fifteenth century, and Alphabeto Musical or mixed tablatures (much used in the XVIIth and XVIIIth centuries). The tablature notation is widely used in informal ways of learning plucked strings instruments nowadays. The specificity of such a system promoted the obliteration of these historical records on textbooks and all formal literacy until recently. The Brazilian university has not brought them to light.

\section{A notação do gesto musical nas cordas dedilhadas: tablaturas}

Segundo JENSENIUS et al. (2010) o "gesto musical é um padrão mocional que produz música, está codificado na música, ou é realizado em resposta à música"2. Na literatura musical, a terminologia aproximada se refere a: "...deslocamento / movimento (Shaffer 1980; Cabrielsson 1985; Clarke 1993; Davidson 1993), movimento expressivo (Pierce and Pierce 1989; Davidson 1994) ou articulações corporais (Leman 2008)", termos utilizados para denotar vários tipos de gestos.

Tal conceito fora aplicado à notação musical convencional de articulações específicas da técnica instrumental, como os signos $\checkmark$ (arco para cima) ou $\Pi$ (arco para baixo) utilizados na família das cordas friccionadas. Inúmeros trabalhos acadêmicos incluem tal conceito ao tratar das técnicas estendidas no repertório contemporâneo da música instrumental e suas respectivas representações gráficas.

A história da notação musical demonstra a complexidade dos sistemas utilizados a partir da adoção de convenções em sua representação gráfica. MAMMI (1999) relaciona a evolução dos sistemas de notação musical com a mudança do pensamento filosófico relativo às artes. Em seu artigo sobre notação gregoriana, o autor trata das várias modalidades de escrita segundo o critério espaço/tempo.

2 "...mus-ical gesture is an action pattern that produces music, is encoded in music, or is made in response to music." Jensenius et al. (2010), p. 19. 
carater icônico da escrita musical moderna se baseia em duas analogias preliminares: o correr do tempo é representado no papel por um movimento de esquerda para direita; a oposição grave/agudo é realizada graficamente pela oposição baixo/alto. Essas correspondências são arbitrárias, e portanto simbólicas. Todavia, não são signos, mas apenas convenções que permitem a criação de um campo de representação. A primeira delas é bastante óbvia, porque deriva do movimento da escrita. A segunda é mais problemática e mais recente. Com efeito, a música grega adotou por muito tempo a relação invertida, como testemunham os nomes das notas: hypate hypatón (a mais alta das altas) era o nome grego do SI, nota mais grave do tetracordo mais grave do sistema[...]; o lá, nota mais aguda, era chamada nete hyperboláion, (a mais baixa das notas acrescentadas) (p.5).

Os signos adotados na codificação musical variavam de códigos representativos do movimento melódico (notação sangaliana e neumática - figuras l e 2) a códigos absolutos de representação dos sons (daséia - figura 3).

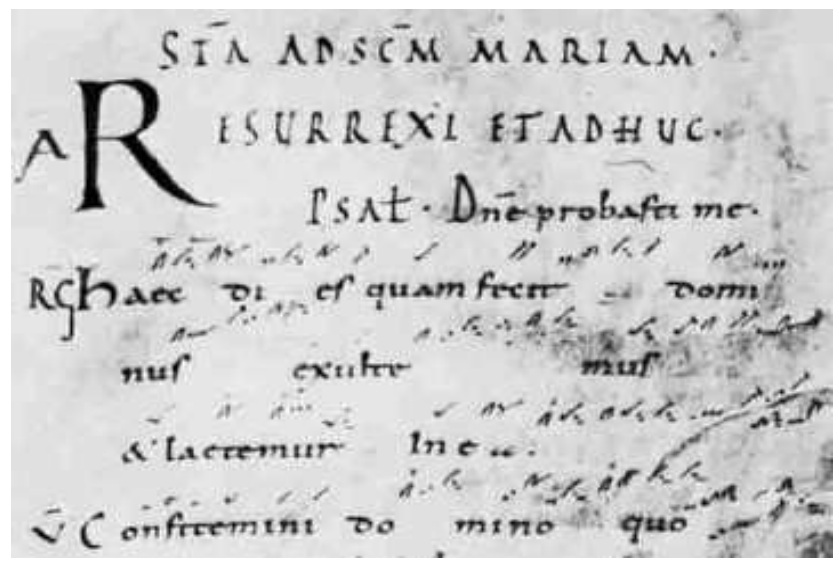

Figura 1: Manuscrito de St. Gall 359 (c.900). 


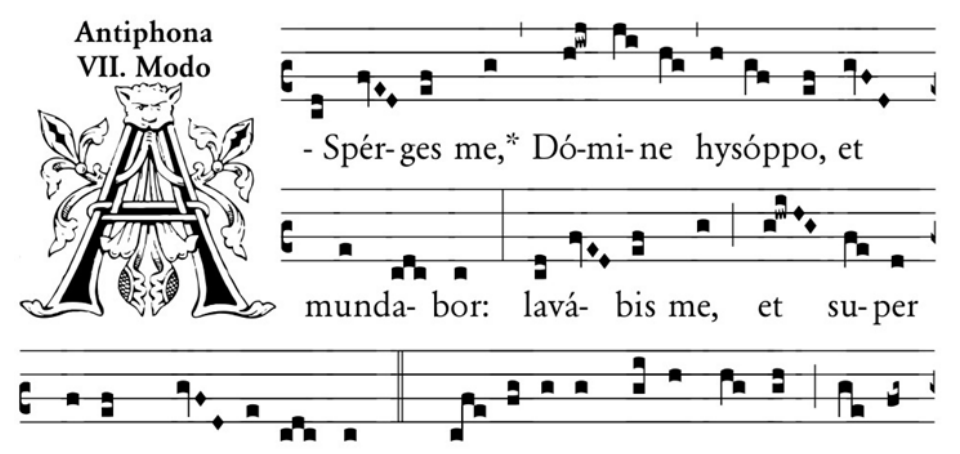

ni-vem de- albá- bor. X̀ Mi- se-ré-re me- i, De- us, ${ }^{*}$ se-cún-

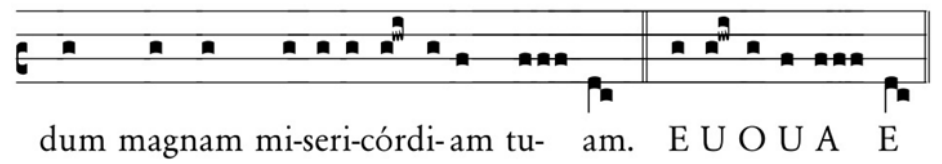

Figura 2: Antífona do Kyriale Romanum.

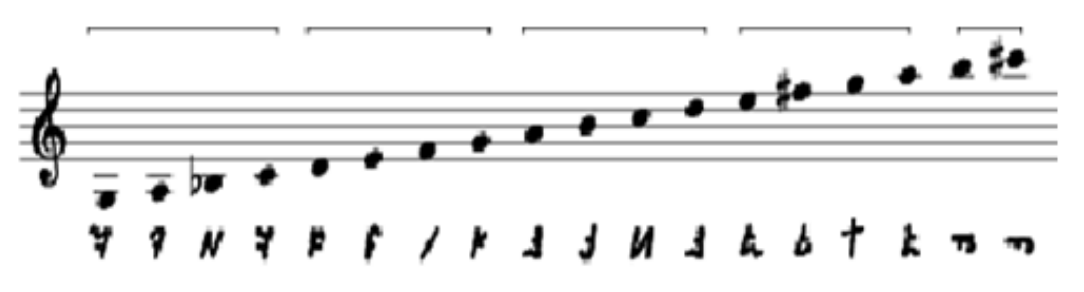

Figura 3: Signos daseianos in HILEY (1993, p.393).

Todo conjunto de notação simbólica demanda algum aprendizado, ensejando maior dedicação quanto mais complexidade se encontre em um ou outro sistema de representação gráfica. A notação moderna da música, cujos fundamentos remontam ao período dito renascentista, teve como herança as transformações advindas do pensamento artístico-musical, suas demandas sonoras, acústicas, expressivas, estruturais e formais. Para além de transformações dos códigos de notação, o sistema incorporou signos de representação 
dos mais variados fenômenos da expressão musical, chegando ao que hoje referimos como notação musical moderna. Diferente das notações mais antigas já encontradas, que se baseavam na escrita verbal grega e incluíam elementos de sua enunciação, a notação incorporada pelo aprendizado musical moderno e, em particular, por aquele institucionalizado, é específica, abrange elementos que se relacionam com seu significado de forma simbólica (representação convencional de seu objeto) e, por essa razão, possui múltiplos aspectos de aprendizado que produziram tratados teóricos da escritura e da enunciação musical. Assim, o sistema de ensino musical foi estruturado a partir de cada um desses aspectos advindos da complexidade de escrita e de representação gráfica da música e, a partir dela, surgiram novas disciplinas interdependentes do sistema de notação.

Em paralelo, as cordas dedilhadas produziram um sistema de notação que, por sua representação gráfica das cordas (ou ordens de cordas ${ }^{3}$ ) do instrumento, constituiu-se em um modelo iconográfico de notação que perdura por séculos, desde os primórdios da imprensa. Suas variantes compreendem os signos indiciários das alturas segundo sua posição no braço do instrumento e são representadas por números (tablaturas italiana e espanhola) ou por letras do alfabeto (tablatura francesa). Seguem as convenções espaciais de altura da notação convencional (agudo na parte superior) as tablaturas francesa e espanhola (figuras 4 e 5). Já a tablatura italiana, a de maior classificação iconográfica, reproduz as alturas conforme a representação visual do braço do instrumento: grave em cima e agudo nas linhas inferiores (figura 6).

${ }^{3}$ Conjuntos de cordas duplas ou triplas. 


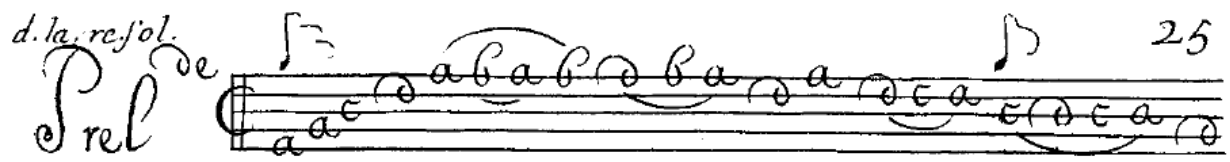

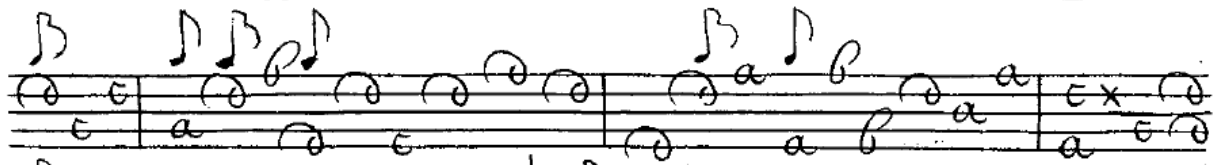

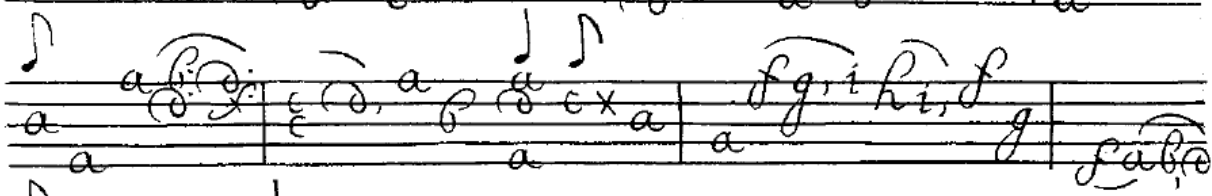

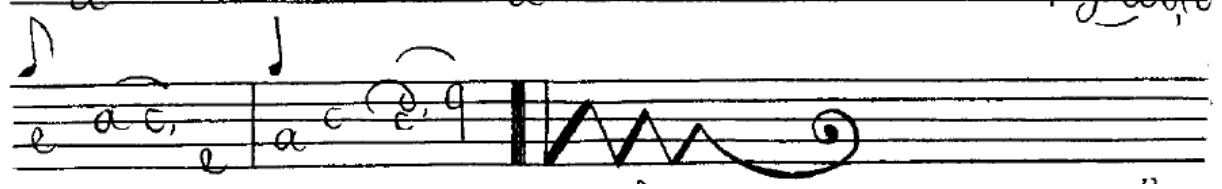

Figura 4: Tablatura francesa: Francesco Corbetta La guitarre royalle ( 1671 ).

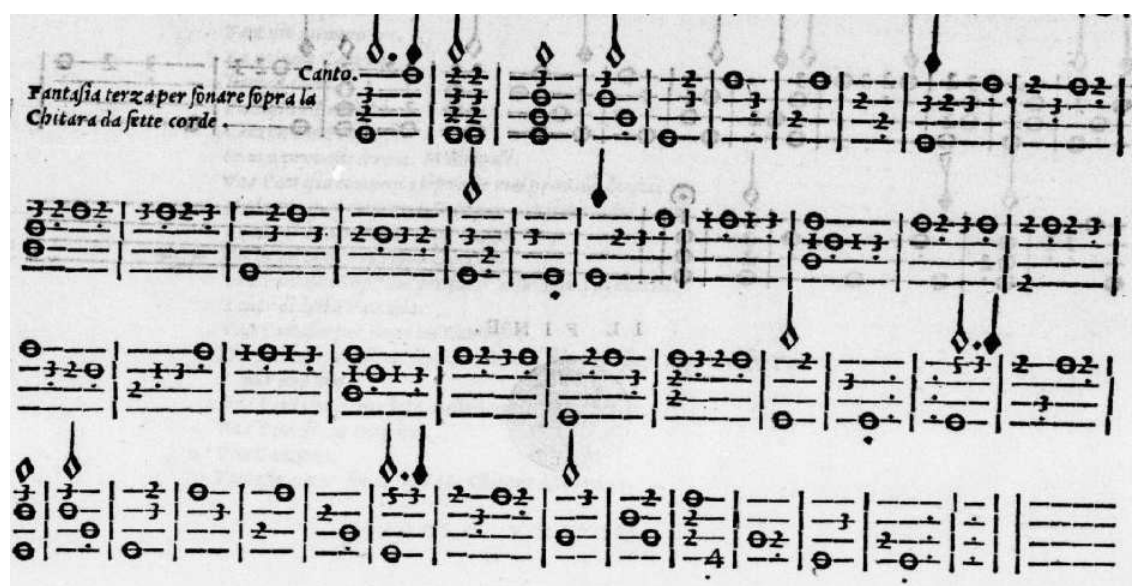

Figura 5: Tablatura espanhola: Melchioro de Barberis Padoano - 1549. 


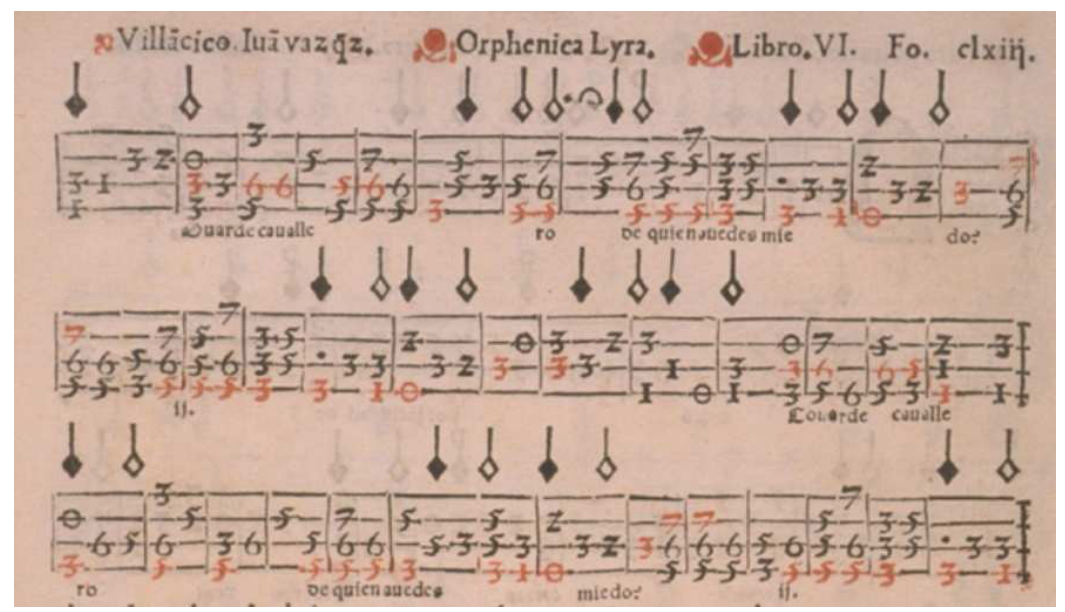

Figura 6: Tablatura italiana: Miguel de Fuenllana Orphenica Lyra (1554).

Esse sistema de notação musical comporta a mesma disposição temporal e os mesmos códigos rítmicos simbólicos da notação convencional, omitindo, tão somente, a repetição imediata de signos iguais. Tal representação implica em menor comprometimento visual da partitura. Em análise mais detalhada, a abrangência dos elementos musicais representados inclui: instrumento;

alturas - representação da exata localização no braço do durações - codificação similar à notação musical convencional; articulações - utilização dos mesmos códigos da notação musical convencional;

ornamentos - signos próprios que variam conforme o autor; digitação de mão esquerda - pontos colocados ao lado dos códigos de alturas em letras ou números;

digitação de mão direita - pontos localizados abaixo dos códigos de alturas;

métrica - mesmos códigos da notação musical convencional; rasgueado - direção do movimento e timbre (digitação específica da mão direita) - figura 7 .

Detalhes de interesse histórico-musicológico apreendidos nesses documentos não foram analisados nos tratados teóricos, 
visto que tal sistema de notação demanda interesse específico de seus instrumentistas $e$, apenas recentemente (segunda metade do séc. $X X)$, o estudo sobre as tablaturas passou a integrar um dos campos da musicologia. A exemplo de uma análise musicológica das tablaturas, reflito sobre a possibilidade de uma prática tardia comum aos trovadores de cantar e se acompanhar ao instrumento. Algumas tablaturas de compositores espanhóis continham signos representados graficamente em vermelho de modo a ressaltar a linha melódica da voz, e o respectivo texto era grafado abaixo desses signos (figura 6 acima). Sabemos que a tradição popular é pautada em tal prática. Contudo, os registros das práticas da música de elite se atêm aos documentos onde a escrita vocal é separada da instrumental. Importantes contribuições históricas das cordas dedilhadas deixaram de ser estudadas e analisadas em virtude de sua notação musical específica.

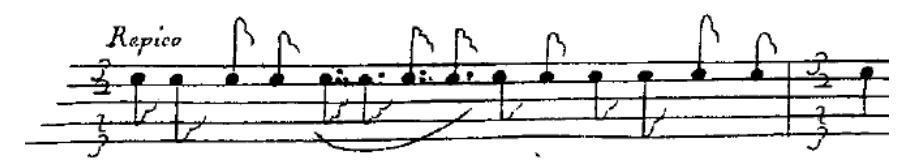

Figura 7: Francesco Corbetta - La guitarre royalle $(|67|)$

A figura 7 mostra o acorde (Dó maior), o ritmo (colcheias e semicolcheias) e o timbre resultante de sua precisa execução pela mão direita: direção do rasgueado através da direção das hastes das notas, dedos utilizados no rasgueado pela analogia do tamanho das hastes com o polegar (haste maior) e indicador (haste menor), além do indicativo dos dedos médio (dois pontos ao lado da nota) e anular (três pontos) em passagens rápidas.

Há que se observar a precisão na codificação da digitação, possivelmente constituinte dos primeiros registros históricos onde tal demanda teve lugar no repertório da música instrumental. Os primeiros registros de digitação da guitarra clássica (guitarra francesa ou violão) incorporaram signos advindos da notação em tablatura (figuras 8 e 9). 


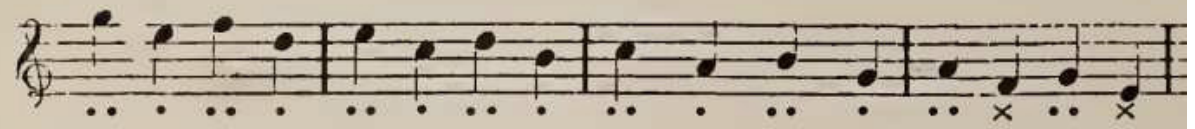

Figura 8: Matteo Carcassi New and Improved Method for the Guitar - 1889.

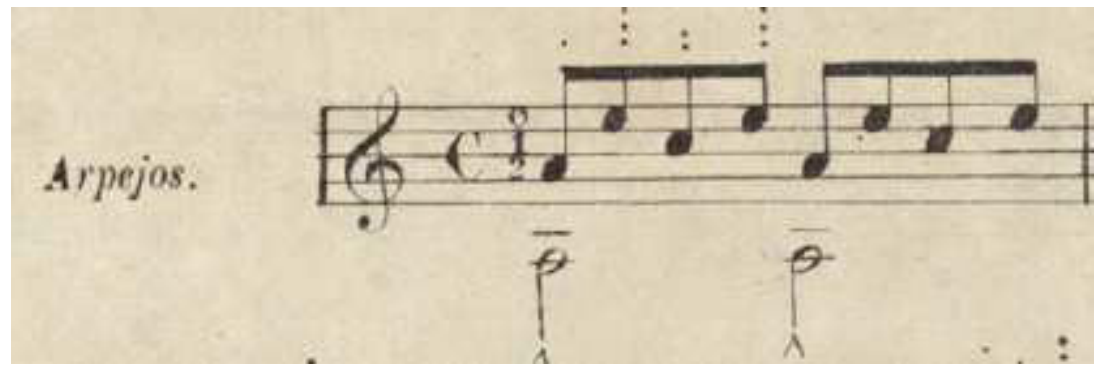

Figura 9: Manuel Nunes Aguedo - Methodo Ceral para Viola Franceza (1856).

\section{Alfabeto musical ou tablaturas mistas: a prática do contínuo nas cordas dedilhadas}

Sabemos que a prática do acompanhamento improvisado, conhecido como baixo contínuo, deu origem a um sistema de notação primeiramente utilizado (e possivelmente criado) por organistas como Lodovico Crossi da Viadana (Cento concerti ecclesiastici.. - 1602) e Agostino Agazzari (Del sonare sopra il basso - 1607), intitulado baixo cifrado. Este consiste em uma linha de baixo (clave de Fá) com cifras numéricas correspondentes aos intervalos das notas (em relação à nota do baixo) que deverão ser executadas simultaneamente à linha do baixo. Esse sistema de notação simbólica foi muito difundido nos séculos XVII e XVIII por quase toda a Europa.

Alguns alaudistas publicaram edições em tablatura de realizações do baixo contínuo para chitarrone ${ }^{4}$, como Johannes

${ }^{4}$ Instrumento grave da família dos alaúdes. 
Hieronymus Kapsberger, para alaúde renascentista, como John Dowland, entre outros.

Ao par da notação do baixo cifrado, surge o alfabeto musical (ou abecedario) para as guitarras, que consiste em uma notação simbólica formada por cifras em letras e alguns signos representativos de acordes específicos. Tais cifras não mantêm relação direta com as cifras medievais da Scholia Enchiriadis, Oddonicas ou outras, nem mesmo com a escrita germânica para teclados (ver APEL, 1953). Sua lógica reside, provavelmente, no formato dos acordes no braço do instrumento, começando por aqueles cujas tonalidades, mais propícias à afinação da guitarra, demandam utilização de um menor número de cordas pisadas com a mão esquerda e progredindo para os acordes de digitações mais complexas, bem como para acordes derivados das primeiras posições (figura 10).

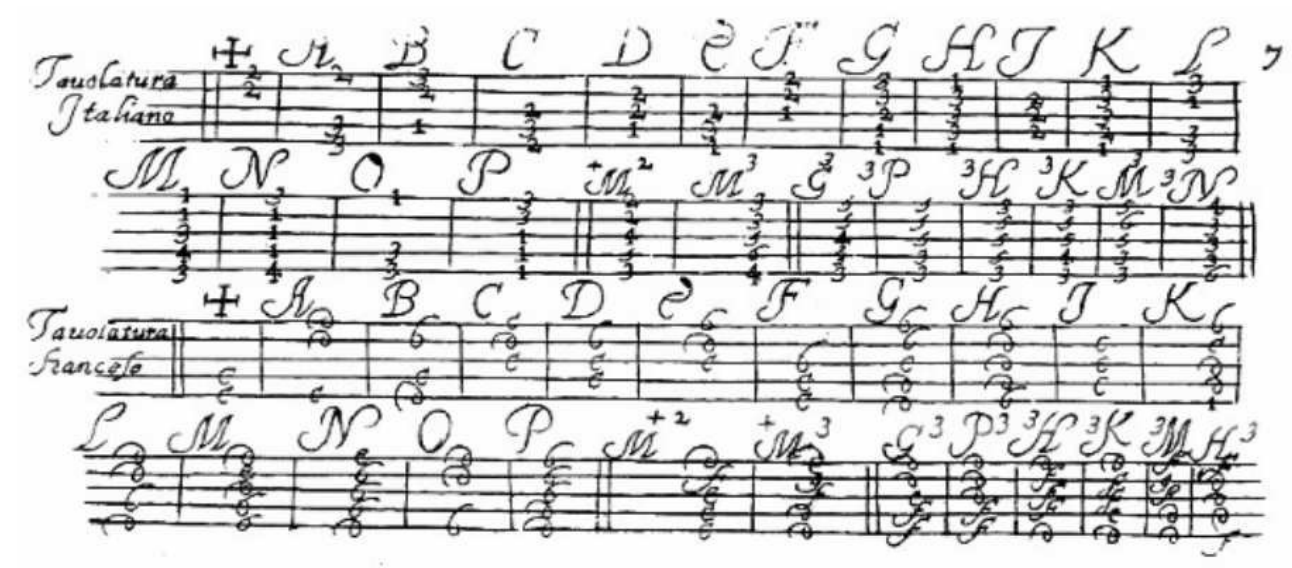

Figura 10: Francesco Corbetta (1648).

Gaspar Sanz também utiliza a cruzeta como ponto de partida dos acordes, inserindo outro signo (o E) para complementar seu alfabeto. 


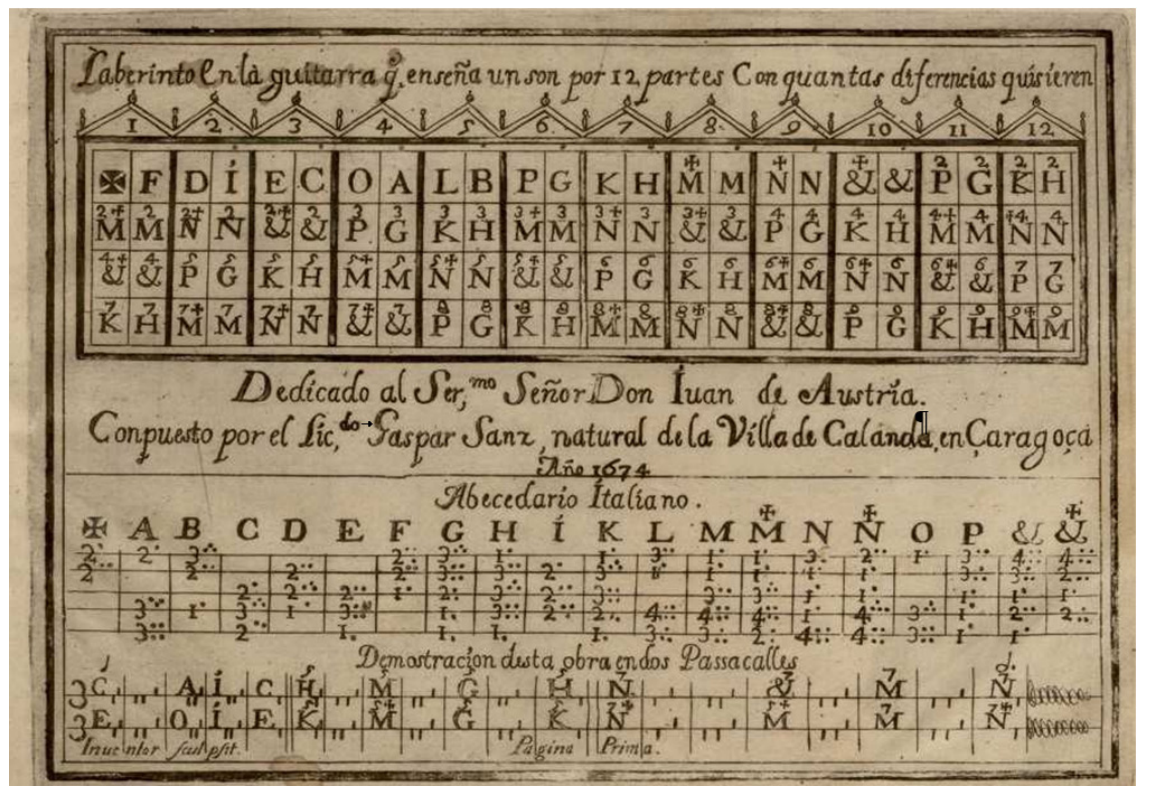

Figura 11: Gaspar Sanz - pagina prima tomo I (1674).

Em seu labirinto en la guitarra, Sanz dispõe os acordes maiores e menores por tonalidade, em progressão de quintas descendentes, e demonstra quatro possibilidades de posicionamento de cada acorde na guitarra. Já na publicação de 1697, Gaspar Sanz oferece um alfabeto cuja codificação não poderia ser mais icônica - figura 12. 


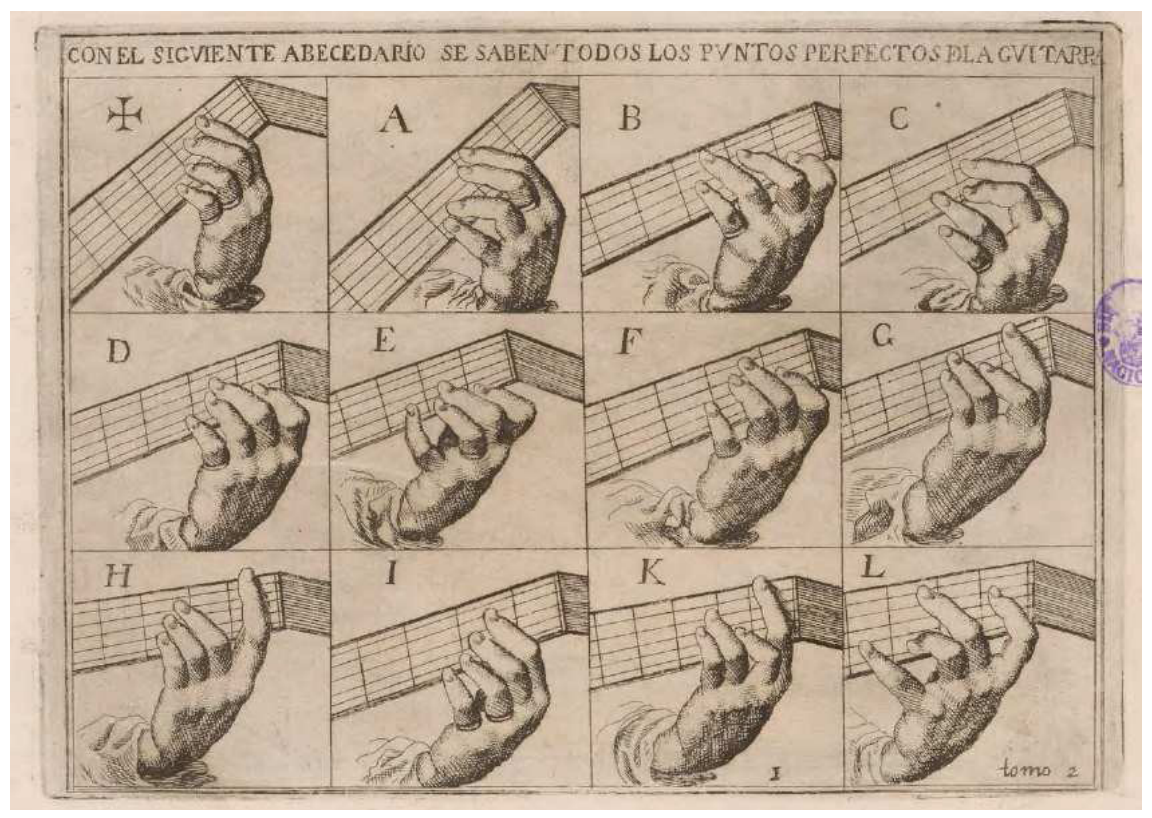

Figura 12: Gaspar Sanz p. 1 I tomo || (1697).

Outro elemento importante ressaltado nessa publicação é o uso das dissonâncias ou falsas.

Seu alfabeto inclui cifras para tais acordes - figura 13. 


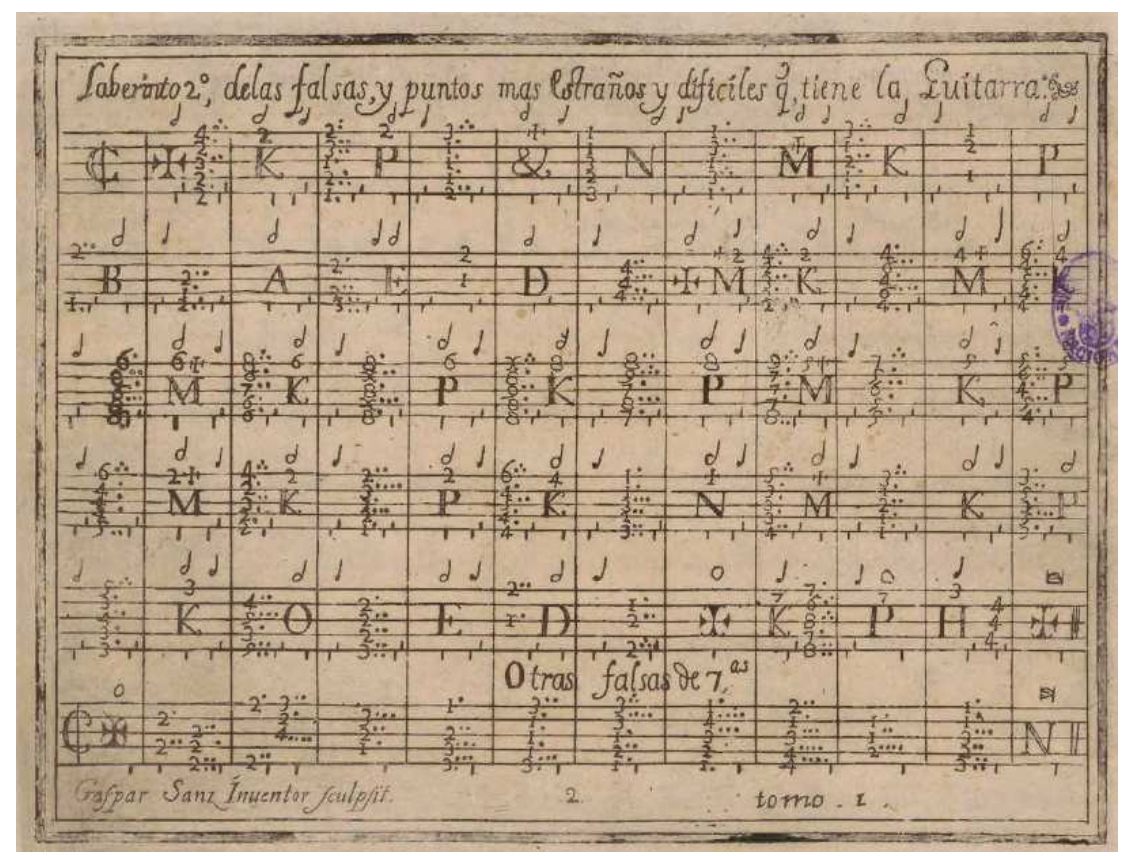

Figura 13: Gaspar Sanz p.2 tomo I (1697).

Este segundo labirinto é oferecido para a prática dos acordes na mesma progressão por quintas e acrescenta códigos simples de rasgueado em métrica binária (pequenos traços verticais acima e abaixo da linha inferior) com a notação rítmica e a digitação dos acordes.

Uma completa instrução para a prática do baixo contínuo cifrado e não cifrado também foi contemplada na publicação de Sanz (1697). O autor demonstra a realização dos acordes para cada cifra na linha do baixo ou para progressões cromáticas e diatônicas - figura 14. 


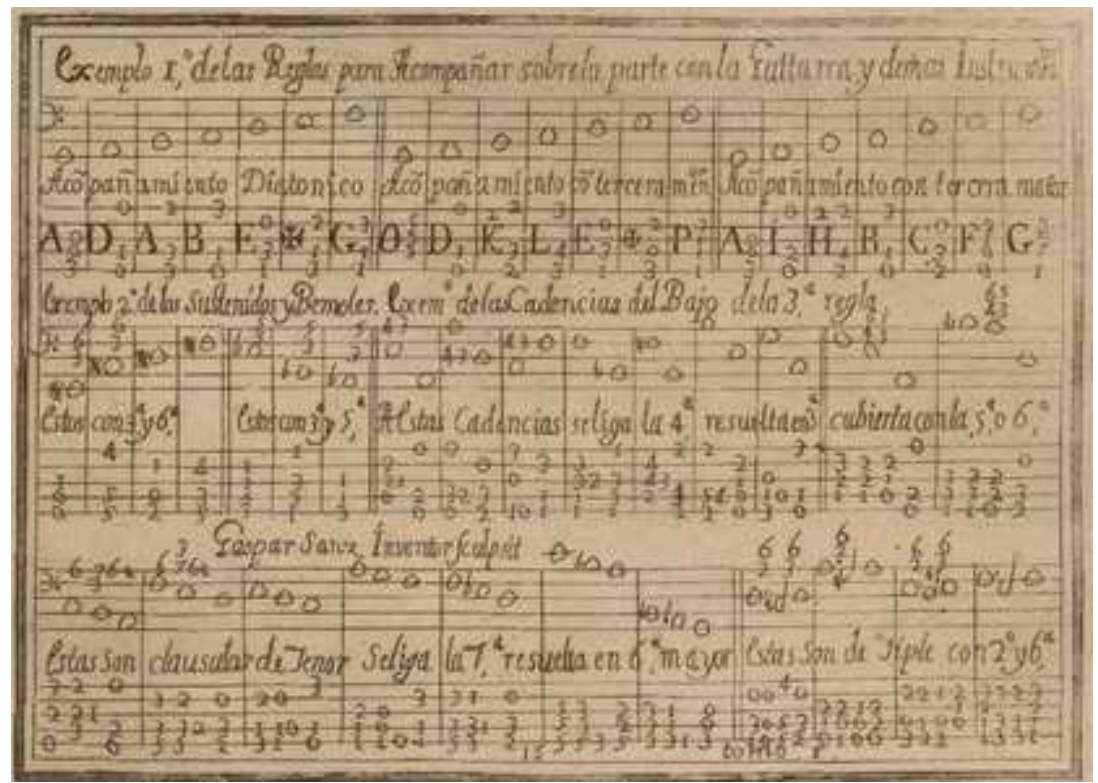

Figura 14: Gaspar Sanz p.13 tomo I (1697).

As tablaturas mistas são, portanto, aquelas que incluem as cifras do alfabeto musical em sua notação, assim como inúmeros detalhes de sua execução. Trata-se de uma prática importante dos séculos XVII e XVIII, observada pelos guitarristas que se ativeram a criar um sistema próprio e único de notação musical para o aprendizado informal. Se verificarmos o desaparecimento dessas publicações no século XIX e seu retorno nas publicações da música popular na segunda metade do século XX, concluiremos que esse sistema de notação musical jamais caiu em desuso. As publicações musicais compreenderam o repertório das camadas sociais que a elas tinham acesso e buscavam as preferências do mercado europeu (e/ou colonial), que já tinha o piano como seu principal instrumento de formação musical, e o violão (guitarra clássica de 6 ordens simples), que compartilhava da notação musical convencional de todos os demais instrumentos no século XIX. Entendemos, pois, que as notações em tablaturas e cifras de acordes (alfabeto) foram preservadas por meio do letramento musical informal e não passaram pelos crivos editoriais utilizados no século XIX e na primeira metade do século XX. 


\section{Outras formas de notação do gesto musical}

A etnomusicologia entende, a partir de trabalhos como os de Gerhard Kubik, James Koetting e Tiago de Oliveira Pinto, que o registro musical das práticas africanas depende de uma compreensão de seus ritmos e sua métrica, divergentes daqueles de origem europeia que fundamentaram a notação musical que conhecemos no Ocidente. Para a idealização desses registros, uma nova forma de notação do gesto musical, denominada TUBS - Time Unit Box System, desenvolvida por Philip Harland, foi utilizada pela primeira vez por J. Koetting na musicologia em 1970, segundo GRAEFF (20|4).

Os conceitos desenvolvidos têm como fundamento a repetição de padrões rítmico-mocionais ou métrica aditiva (ou, ainda, linha rítmica), em oposição a métrica/compasso como a entendemos. Do artigo de PINTO e GRAEFF, transcrevo as seguintes definições:

- os pulsos elementares são as menores unidades de tempo presentes na música africana, que formam uma matriz subjetiva para a execução musical, de maneira que todo evento sonoro - e também coreográfico e mocional - coincide com um dos pulsos;

- Linha rítmica (Pinto, 1992) ou time-line (Nketia, 1991) - é um padrão rítmico cíclico que [...] possui configuração assimétrica. Uma música marcada por esse tipo de concepção tenderá a acentuações rítmicas igualmente assimétricas.

A aplicação da notação TUBS na notação da viola de machete do Recôncavo Baiano resulta: 
Tom Lá Maior (partes A e B) com indicação dos pulsos elementares, beats e linha-rítmica inerente ${ }^{4}$ :

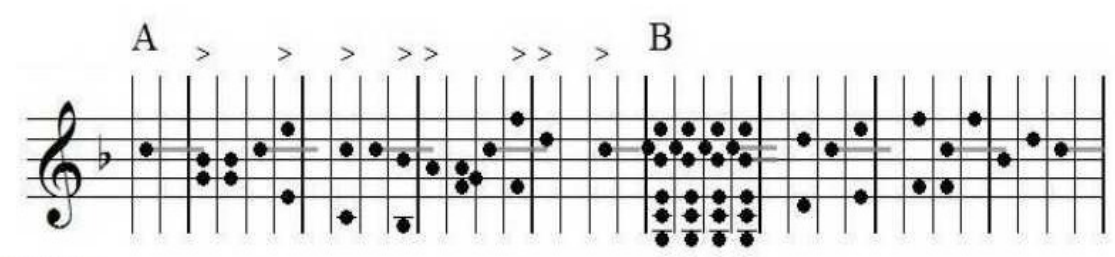

Pulsos Elem.

Beats

Linha-ritmica $x \cdot x \cdot x, x, x \cdot x \cdot x \cdot x, x \cdot x \cdot x \cdot x, x \cdot x \cdot x \cdot x \cdot x, x \cdot x$

$\mathrm{x}=$ Pulso elementar percutido em uma linha-rítmica imaginária $\quad .=$ Pulso elementar vazio

Figura 15: PINTO e GRAEFF (20|4, p.83).

A figura 15 mostra uma linha rítmica formada pela adição de um padrão de 7 beats a outro de 9 beats (métrica aditiva), explicitamente diverso do padrão rítmico do samba conhecido através da notação musical convencional em compasso regular quaternário. A distorção oferecida pela notação convencional infere uma simetria regular inexistente na prática cultural africana.

Outro exemplo de linha rítmica 7+9 com acentos ainda mais assimétricos, encontrei no Documentário Cantador De Chula, de Marcelo Rabelo, filmado no Recôncavo Baiano, no
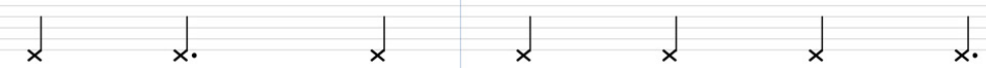

Figura 16: Excerto de 0:43:00 a 0:48;40 minutos.

Analisando a transcrição realizada por Craig Russel do rasgueado da dança Cumbees do Códice Saldivar $n^{10}$. 4, que inclui a percussão em seus movimentos, tratei da aplicação do conceito de time-line de forma a verificar diversas possibilidades de acentuação. Os resultados foram: 


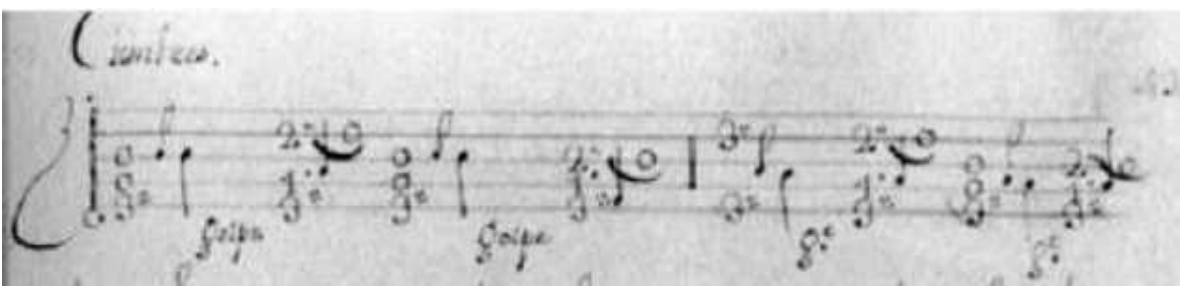

Figura 17: Fac-símile Códice Saldivar $n^{\circ} 4$.

Transcrição do time-line de Cumbees:

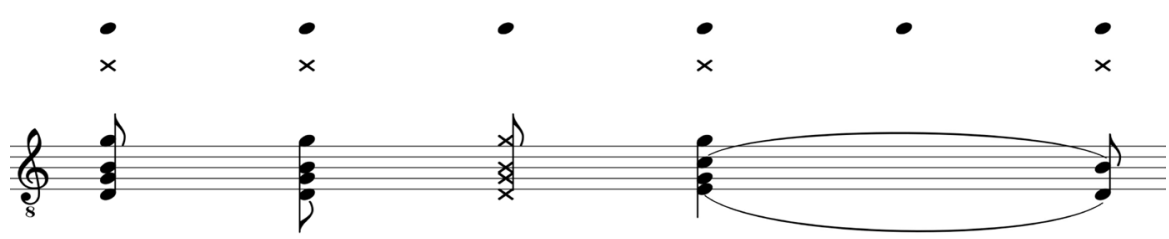

Figura 18: transcrição do time-line diretamente da tablatura
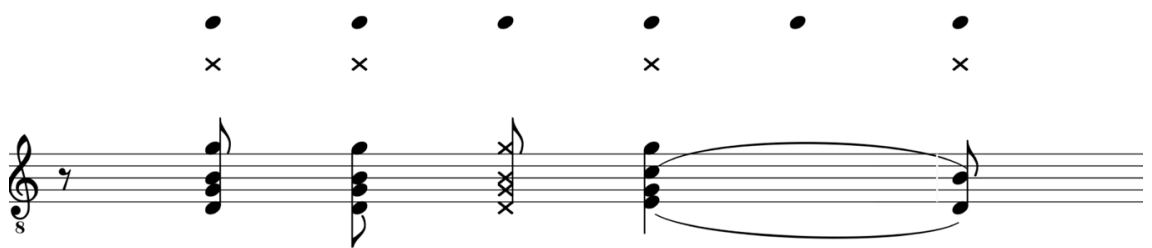

Figura 19: transcrição com pausa inicial para ajuste a um possível compasso ternário

A tablatura não oferece uma pausa inicial e a sequência do ponteado após o rasgueado inicial sugere métrica de 6 beats. Contudo, o ritmo encontrado no time-line sugere o segundo acorde como o mais acentuado, situação esta que prescindiria da pausa inicial e configuraria o primeiro acorde como anacruse na escrita musical convencional.

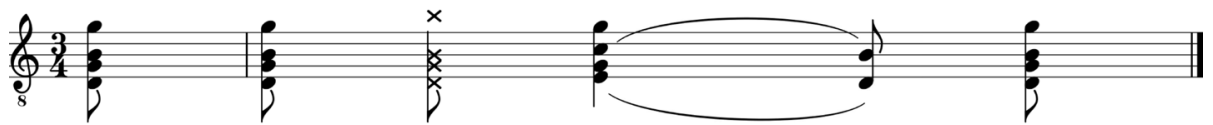

Figura 20: transcrição ajustada a compasso ternário 
Craig Russel atribui esta publicação da primeira metade do século XVIII a Santiago de Murcia, guitarrista barroco espanhol de grande importância para a pesquisa musicológica sobre as cordas dedilhadas. A compilação de Murcia é justa em relação aos tempos do ponteado de modo a caber em uma métrica ternária/binária $(\mathbf{3} / \mathbf{6}$ ) e segue o padrão
mocional da figura 19 .

Tais suposições têm como fundamento a riqueza rítmica das práticas musicais africanas e possibilitam novas leituras de textos musicais históricos.

\section{Modalidades de aprendizagem dos instrumentos de cordas dedilhadas}

Após o apogeu das cordas dedilhadas nos séculos XVI e XVII, contando com centenas de publicações em forma de coletâneas/métodos de música instrumental no período, o século XVIII marcou algumas tentativas de aproximação da escrita para alaúdes na França com a notação convencional dos demais instrumentos, de modo a possibilitar a execução de seu repertório principalmente pelo cravo e evitar sua impopularidade. Contudo, o resultado é retratado por Titon du Tillet que escreveu em 1732 sobre os alaúdes: "Eu não acredito que alguém possa encontrar em Paris nos dias de hoje mais do que três ou quatro veneráveis anciãos que toquem o instrumento" 5 . Paralelamente, as guitarras de cinco ordens ainda contavam com certa apreciação do público e obtiveram mais de 50 publicações naquele século de tratados e coleções de obras instrumentais, principalmente na Itália, França e Espanha, e uma centena de obras para acompanhamento das guitarras (em grande número notadas em alfabeto musical). Algumas publicações denominam o instrumento como violas portuguesas (Juan Amat, João Leite Pica da Rocha - ambas de 1752) ou simplesmente viola (Manuel da Paixão Ribeiro - 1789).

Todo aprendizado das guitarras/violas se deu no âmbito informal no século XIX, já que jamais constaram da documentação curricular de instituições formais de ensino da música, a exemplo do

5 Apud MASSIP (1976). 
Estatuto do Conservatório de Música (fundado no Rio de Janeiro em 1841), publicado pelo Decreto n. 8226 de 20 de agosto de 1881 (figura 21 ).

\section{(.APITUI, J}

DA ORGANIZAGT̃O JO CONSERYITORTO DF MUSICA

Art. 1." Esta inslituçôn a destimata ao ensino srratuito da musica vocal e intrin entil.

Att. 2." O ensimu ce dirá nas seguinters anlas:

be rublimentos de musica. solfaju rollectivo e individual,

e noçoes geraes do eallto. bara a sero maseulino ;

Idem pira o sexo feminino;

Do canto;

De piano (estudo do teclado, excrcicios graduados, pecas faceis) ;

De piano (peças diffireis);

De liutata ;

De elirinula;

De ribrea ;

De violoncello e conlraluaiso;

De trompa e autros instamintos de motal;

De regras de larmonit, e li harmonia acompanhamento praticos.

Figura 21: Estatuto do Conservatório de Música publicado em 1881.

Já o violão ( 6 ordens simples) ou guitarra francesa, como era conhecido no Brasil do século XIX, esteve presente na vida musical das elites, como comprovam os estudos de Márcia Taborda, professora e pesquisadora da UERJ. Seu aprendizado unicamente informal ocorreu no Rio de Janeiro por meio de aulas particulares divulgadas em anúncios na mídia impressa. Sabemos também da utilização de métodos para seu aprendizado em notação musical convencional, como o op.59 de Matteo Carcassi, em oposição a nenhum registro em tablaturas ou tablaturas mistas.

Sobre as formas de aprendizado, MARCUSCHI (2010) defende a concepção de que língua e texto (fala e escrita) são vistos como um conjunto de práticas sociais e que o letramento podese dar em contextos não-formais: letramentos sociais. Esta posição contraria a idéia da primazia da escolarização do letramento, tida por muitos autores como única, sobre outras práticas. 
O letramento é um processo de aprendizagem social e histórica da leitura e da escrita em contextos informais e para usos utilitários...(p.21)

A escolarização, por sua vez, é uma prática formal e institucional de ensino que visa a uma formação integral do indivíduo...(p.22)

A oralidade seria uma prática social interativa para fins comunicativos que se apresenta sob variadas formas ou gêneros textuais fundados na realidade sonora [...] $\bigcirc$ letramento envolve as mais diversas práticas da escrita (nas suas variadas formas) na sociedade [...] e se manifesta em diferentes níveis de apropriação... (p.26)

Seguindo a concepção de Marcuschi, as tablaturas são consideradas formas de notação musical que pressupõem letramento, já que tratam de processos de leitura e escrita. A história nos demonstra a informalidade de tal letramento, excluído das institutições de ensino musical europeias até meados do século $X X$, e ainda hoje das instituições brasileiras de ensino musical superior. Seu aprendizado se deu pela mídia impressa até fins do século XVIII e pela informalidade das práticas populares até hoje.

As demais práticas de aprendizado das cordas dedilhadas e, em particular, das violas, ocorrem na oralidade das tradições populares, dentro do contexto cultural de suas manifestações, e são responsáveis pela maior parte do conhecimento histórico que detemos sobre as cordas dedilhadas no Brasil. Prescindem da escrita, enaltecendo a habilidade e o talento inatos de seus instrumentistas.

As duas formas de aprendizado informal das cordas dedilhadas no Brasil constituem universos culturais paralelos da iniciativa popular.

As práticas ditas "da música antiga" incorporaram o ensino das tablaturas históricas no âmbito da escolas técnicas de música (em número ainda pequeno no Brasil), bem como das tablaturas modernas no ensino da música popular, além de utilizarem e difundirem os inúmeros aplicativos de edição digital de partituras/tablaturas. 
Cabe, então, uma reflexão sobre o ensino superior de música no Brasil e o aproveitamento da produção de conhecimento em seus projetos pedagógicos.

\section{A música na universidade brasileira}

A tradição do ensino institucional de Música no Brasil deve suas influências aos modelos europeus adotados ainda no período imperial. Tais modelos compreendem o ensino de conteúdos básicos teóricos de leitura e escrita musical (Teoria, Harmonia e outras), práticas individuais e coletivas de canto (Solfejo e Canto Coral), aprendizado de Instrumento/Canto/Regência/Composição e práticas instrumentais em conjunto. Ao analisarmos o Estatuto do Conservatório de Música (figura 21) publicado em 1881, constatamos tal configuração.

Segundo SILVA (2005), a educação musical da elite imperial no Brasil agia como elemento unificador da cultura civilizadora, revelando como objeto a manutenção da ordem pública:
O Conservatório de Música foi organizado seguindo padrões elitistas e enquanto uma realização de um grupo social condutor da política nacional [...] [Alessandra Frota Martinez sobre instrução e educação pública primaria] revela que o sentido de instruir era antes de tudo, dar educação ao individuo, desenvolver seus princípios morais e religiosos, para com isso incentivar o progresso e o bem estar do individuo, fortalecendo seu caráter e tornando-os responsáveis por si mesmos. [...] E o ensino da música pode ser considerado dessa forma, como um dos elementos que buscavam alternativas para a solução (d)a manutenção de uma ordem social que se tornava mais complexa e múltipla, agindo como um elemento unificador da cultura civilizadora.

Observadas as estruturas curriculares de inúmeros cursos de bacharelado em Música disponíveis na internet, constatei algumas variações daquele modelo através da inclusão de conteúdos nas áreas de História, Filosofia e Antropologia da Música. Contudo, o conteúdo central do modelo ainda prevalece. 
Marilia Tozoni-Reis realiza uma reflexão sobre diferentes concepções de educação que contribuem para o entendimento da atual situação do ensino superior de música. A autora aborda duas concepções antagônicas de educação, a saber: a educação como instrumento de reprodução da sociedade e a educação como instrumento de transformação da sociedade.

\begin{abstract}
A educação como instrumento de reprodução da sociedade diz respeito à educação não- crítica, aquela que tem como finalidade principal a adaptação do sujeito à sociedade tal qual ela se apresenta. Se considerarmos que vivemos em uma sociedade desigual, temos que a educação concebida como um processo de adaptação a essa sociedade, como um instrumento de reprodução dessa sociedade, tem como objetivo manter essa sociedade desigual. Obviamente que vemos essa concepção, na prática, em muitos espaços educativos, inclusive escolares.
\end{abstract}

A educação como instrumento de transformação da sociedade refere-se à educação crítica, àquela que tem como finalidade principal a instrumentalização dos sujeitos para que esses tenham uma prática social crítica e transformadora. Isso significa que, em uma sociedade desigual, os sujeitos precisam se apropriar de conhecimentos, ideias, atitudes, valores, comportamentos etc., de forma crítica e reflexiva para que tenham condições de atuar nessa sociedade visando a sua transformação.

Trazendo tais concepções para o âmbito institucional da Música na Universidade brasileira, percebemos que os cursos superiores preservam, em essência, o modelo educacional de reprodução da sociedade. Suas estruturas curriculares são fundamentadas no conceito de disciplina (com raras exceções) cujo conteúdo discriminado em seu programa se torna quase inflexível em razão do complexo processo burocrático existente para a realização de qualquer alteração. Tal imobilidade tem conduzido o ensino superior da Música a certo anacronismo, impedindo a reflexão mais profunda sobre os objetivos gerais dos cursos e a atualização do modelo educacional, em virtude das rápidas mudanças sociais produzidas pelas mídias digitais. 
Cabe refletir, primeiramente, sobre os modelos de gestão universitária de modo a promover maior liberdade aos participantes da vida acadêmica, para flexibilizar os cursos em seus projetos político-pedagógicos. Somente então será possivel realizar uma atualização consistente e contínua do ensino, com base na assimilação de conteúdos da produção de pesquisa acadêmica.

\section{Referências}

GRAEFF, N. Fundamentos rítmicos africanos para a pesquisa da música afro-brasileira: o exemplo do Samba de Roda. In: Revista da Associação Brasileira de Etnomusicologia, vol. 9, 2014.

JENSENIUS, A. R. et al. Musical Gestures:concepts and methods in research In Musical gestures : sound, movement, and meaning. Ed. CODOY, R. I. e LEMAN, M. Nova York: Routledge, 2009.

MAMMI, L. A Notação Gregoriana: Cênese e Significado. Revista Música, São Paulo, v. 9 e 10, pp. 21 -50, 1998-1999.

MARCUSCHI, L. A. Da fala para a escrita: atividades de retextualização. São Paulo: Cortez, 2010.

MASSIP, C. La Vie des musiciens de Paris au temps de Mazarin (1643166 1). Paris: Picard, 1976, p. 29.

PINTO, T. O. e GRAEFF, N. Música entre materialidade e imaterialidade: os tons-de-machete do Recôncavo Baiano. In: Mouseion, n. 1 1, jan-abr, 2012, p. 72-97.

RABELO, M. de. Documentário filmado no Recôncavo Baiano. Publicado em 25 de maio de 2015 - In: https://www.youtube.com/ watch?v=H2Z_5wo7X_s. Acesso em 09/10/16.

RUSSEL, C. ed. Santiago de Murcia's "Códice Saldivar no.4": a treasury of secular guitar music from baroque Mexico, vol. 2, 1995.

SILVA J. G. Conservatório de Música: a ideia de educação musical da elite imperial no Brasil. Anais da ANPUH - XXIII Simpósio Nacional de História, Londrina, 2005. 
TOZONI-REIS, Marilia Freitas de Campos. A pesquisa e a produção de conhecimentos: introdução à pesquisa em educação. Curso de pedagogia da Unesp. 20 10. Disponivel em:

<http://www.acervodigital.unesp.br/handle/123456789/195>.

\section{Sobre o autor}

Doutora em Ciências da Comunicação pela ECA-USP (2008), realizou seu Mestrado em 'Musical Performance' no Royal Northern College of Music (Manchester - 1985) em convenio com The Victoria University of Manchester, e seu Bacharelado em Música com Habilitação em Composição pela Faculdade Paulista de Arte (1980). É Professora dos cursos de Música da Universidade Estadual Paulista Júlio de Mesquita Filho, tendo sido Coordenadora do Conselho dos Cursos de Música por 5 anos. Tem experiência na área de Performance Musical, com ênfase em Instrumentação Musical e Musicologia Histórica, atuando principalmente nos seguintes temas: viola de arame, memória musical brasileira, violão, música barroca e música antiga. Membro do NoMaDH - Núcleo de Musicologia e Desenvolvimento Humano certificado pelo CNPq. 